\title{
REVISITANDO O ESTUDO/ESTATUTO DIALÓGICO DA PALAVRA-ENUNCIADO
}

\author{
Revisiting the Dialogical Revisión del Estudio/Estado \\ Study/Status of the Word-Utterance Dialógico de la Palabra-Enunciado
}

\author{
Rodrigo Acosta Pereira* \\ Universidade Federal de Santa Catarina \\ Centro de Comunicação e Expressão \\ Departamento de Língua e Literatura Vernáculas \\ Florianópolis, SC, Brasil \\ Beth Brait** \\ Pontifícia Universidade Católica de São Paulo \\ Faculdade de Filosofia, Comunicação, Letras e Artes \\ Departamento de Ciências da Linguagem e Filosofia \\ São Paulo, SP, Brasil
}

\begin{abstract}
Resumo: Diversificados e produtivos caminhos de estudo da palavra têm se instituído no campo das ciências da linguagem. Neste artigo, o objetivo é delinear considerações epistemológicas e teóricometodológicas a respeito do estudo da palavra como signo ideológico, a partir dos escritos do hoje denominado Círculo de Bakhtin e, mais especificamente, de M. Bakhtin, V. Volóchinov e P. Medviédev. Para tanto, o artigo revisita o conjunto desses trabalhos e retoma as principais considerações desenvolvidas, centradas na relação constitutiva existente entre signo-ideologia-palavra. $\mathrm{O}$ estudo pretende contribuir para a compreensão da palavra como dimensão semiótico-ideológica, situando a relevância dessa discussão para os estudos de língua/linguagem na perspectiva enunciativo-discursiva e na consolidação dos estudos discursivos que, no Brasil, são denominados Análise Dialógica do Discurso (ADD).
\end{abstract}

Palavras-chave: Círculo de Bakhtin. Signo ideológico. Palavra-enunciado.

Abstract: Diverse and productive ways of studying the word have been instituted in the field of language sciences. In this paper, the objective is to delineate epistemological and theoretical-methodological considerations regarding the study of the word as an ideological sign, from the writings of today called Bakhtin Circle and, more specifically, M. Bakhtin, V. Volóchinov and P. Medviédev. Therefore, the paper revisits the set of these works and returns to the main considerations developed there, centered on the constitutive relation existing among sign-ideology-word. The study aims to contribute to the understanding of the word as a semiotic-ideological dimension, placing the relevance of this discussion for idiom/language

* Professor no Programa de Pós-graduação em Linguística e no PROFLETRAS da UFSC. Pós-doutorando do LAEL/PUC-SP no período compreendido entre 01/08/2018 e 31/07/2019. ORCID: https://orcid.org/0000-0003-0148-8725 .E-mail: drigo_acosta@yahoo.com.br.

** Livre-docente em Linguística pela Universidade de São Paulo (USP). Professora nos Programas de Estudos Pós-graduados em Linguística Aplicada e Estudos da Linguagem (LAEL/PUC-SP) e Literatura e Crítica Literária (LCL/PUC-SP), PUC-SP. Bolsista de Produtividade em Pesquisa do CNPq (PQ-1A). ORCID: https://orcid.org/0000-0002-1421-0848 .E-mail: bbrait@uol.com.br. 
studies in the enunciative-discursive perspective and in the consolidation of the discursive studies, which in Brazil are called Dialogical Discourse Analysis (ADD).

Keywords: Bakhtin Circle. Ideological sign. Word-utterance.

Resumen: Diversos y productivos caminos de estudio de la palabra se han instituido en el campo de las ciencias del lenguaje. En este artículo el objetivo es delinear consideraciones epistemológicas y teóricometodológicas acerca del estudio de la palabra como signo ideológico, a partir de los escritos del hoy denominado Círculo de Bakhtin, y, más específicamente, de M. Bakhtin, V. Volóchinov y P. Medviédev. Para ello, el artículo revisa el conjunto de esos trabajos y retoma las principales consideraciones desarrolladas, centradas en la relación constitutiva existente entre signo-ideología-palabra. El estudio pretende contribuir a la comprensión de la palabra como dimensión semiótico-ideológica, situando la relevancia de esa discusión para los estudios de lengua/lenguaje en la perspectiva enunciativo-discursiva y en la consolidación de los estudios discursivos, que en Brasil se denominan Análisis Dialógico del Discurso (ADD).

Palabras clave: Círculo de Bakhtin. Signo ideológico. Palabra-enunciado.

“A palavra, so(m)bra da ação".

(Demócrito/José Paulo Paes) ${ }^{1}$

\section{CONSIDERAÇÕES INICIAIS}

Diferentes perspectivas de estudo da palavra têm caracterizado o campo dos estudos linguísticos, enunciativos e discursivos, propondo encaminhamentos teóricos e metodológicos que, grosso modo, se fundamentam na lógica das relações intrassistêmicas, por um lado, ou nas relações intersubjetivas de sujeitos em contextos sociais múltiplos, por outro. Seria impossível elencar aqui o conjunto dos importantes e significativos estudos desenvolvidos no universo dessas duas tendências, assim como suas fecundas e produtivas contribuições aos estudos da linguagem. Contudo, dado o escopo deste artigo - os estudos dialógicos da linguagem - podemos considerar que, à luz das discussões de Volochínov (2013d [1928], p. 101-103) sobre as tendências do pensamento linguístico ocidental ${ }^{2}$, o estudo da palavra poderia estar associado a duas orientações: a do subjetivismo individualista e a do objetivismo abstrato. ${ }^{3} \mathrm{Ou}$ ainda, sob o escopo dos estudos acerca do discurso interior, podemos entender que, a partir do que Bakhtin [Volochínov] (2009 [1927]) $)^{4}$ explica sobre os campos de estudo da psicologia e

\footnotetext{
${ }^{1}$ PAES (1986).

${ }^{2}$ Aqui Volochínov se refere aos estudos do final do século XIX e início do século XX, mas que ainda trazem reverberações aos estudos atuais no campo das ciências da linguagem.

${ }^{3}$ Não vamos tratar extensivamente dessas orientações. Para tanto sugerimos a leitura do ensaio As mais recentes tendências do pensamento linguístico ocidental, de Volochínov (2013 [1928], p. 101-130).

${ }^{4}$ Embora a tradução brasileira de $O$ freudismo traga o nome de Bakhtin, as pesquisas atuais, assim como traduções para outras línguas, identificam o texto como sendo de Volóchinov. A esse respeito, Sheila Grillo afirma: "Embora a tradução brasileira traga o nome de Mikhail Bakhtin, esse texto foi publicado por Volóchinov e fez parte das atividades descritas nos relatórios apresentados ao "Instituto da História Comparada das Literaturas e das Línguas do Ocidente e do Oriente" (ILIAZV), lugar de atuação de Valentín Nikoláievitch Volóchinov entre 1925 e 1932” (GRILLO, 2017, p. 55, nota 3).
} 
sua relação com a filosofia da linguagem ${ }^{5}$, a palavra poderia ser entendida sob duas perspectivas: a da psicologia comportamental/objetivista e a da psicologia subjetivista/experimental ${ }^{6}$. Em resposta a ambas as orientações (filosóficas e psicologistas), Volochínov e Bakhtin/Volochínov reiteram uma terceira posição, uma orientação sociológica.

Reconhecendo essa realidade teórica, o objetivo geral deste artigo é discutir, epistemológica, teórica e metodologicamente, a concepção de palavra na perspectiva dialógica-sociológica, isto é, da palavra-enunciado, de certa forma aqui incluída na terceira tendência/orientação acima enunciada. Para tanto, o estudo, de escopo bibliográfico, consistirá essencialmente em retomar considerações de Bakhtin e o Círculo, em especial as que têm, dentre outros, o propósito de explicar o estudo da palavra como enunciado, isto é, sua natureza histórica, social e viva.

Dado o caráter das postulações do Círculo, este estudo, necessariamente, oferecese como movimento transfronteiriço, como se verá. O texto organiza-se em sete seções, sendo cada uma (com exceção destas considerações iniciais, da seção 6 e das considerações finais) indicativa das propriedades dialógicas da palavra: (i) natureza semiótico-ideológica; (ii) neutralidade ideológico-valorativa; (iii) possibilidade de interiorização; (iv) ato enunciativo.

\section{A NATUREZA SEMIÓTICO-IDEOLÓGICA DA PALAVRA}

Volóchinov (2017 [1929/1930]) explica que toda forma de compreender e apreender a realidade social da qual fazemos parte, como sujeitos, se dá por meio de signos. Os objetos do mundo social adquirem funções outras como resposta às diferentes situações de interação, passando a significar além de suas particularidades materiais, tornando-se signos. Ou seja: o signo é, por assim dizer, a forma material da realidade e é ele que possibilita a pluridiversificação dos modos de (re)conhecer essa realidade. Essa pluridiversificação realiza-se em concomitância com a ideologia (VOLÓCHINOV, 2017 [1929/1930]; MEDVIÉDEV, 2012 [1928]), entendida como "[...] todo o conjunto de reflexos e interpretações da realidade social e natural que se sucedem no cérebro do homem, fixados por meio de palavras, desenhos, esquemas e outras formas sígnicas" (VOLOCHÍNOV, 2013a [1930a], p. 138, nota 5, destaques do autor).

Assim considerado, o signo, qualquer que seja sua materialidade (verbal, visual, verbo-visual, verbo-gestual, etc.) é ideológico e a ideologia, por sua vez, só se realiza por meio de signos: "[...] onde não há signo também não há ideologia" (VOLÓCHINOV, 2017 [1929/1930] p. 91). Se sem signos não existe ideologia, e vice-versa, é preciso compreender que o material de realização concreta do signo ideológico, segundo o Círculo, é a palavra, que não apenas dá forma ao signo como, dada a gênese ideológica deste, satura-se de modos plurais de produção de sentido e efeitos de sentido. Toda

\footnotetext{
${ }^{5}$ Estudo de Bakhtin/Volochínov sobre Freud à luz da filosofia da linguagem.

${ }^{6}$ Não vamos tratar extensivamente dessas orientações. Para tanto sugerimos a leitura da obra O Freudismo, de Bakhtin [Volochínov] (2009 [1927]).
} 
palavra, portanto, é necessariamente semiótico-ideológica, refletindo e refratando ${ }^{7}$ realidades.

\begin{abstract}
A expressão semiótico-ideológica está sendo utilizada [...] com base na articulação de ideias presentes em dois textos do Círculo: O problema do texto na linguística, na filologia e em outras ciências humanas, conjunto de anotações feitas por Bakhtin entre 1959 e 1961, não revistas, mas publicadas em Estética da criação verbal [e mais recentemente, em nova tradução, $O$ texto na linguística, na filologia e em outras ciências humanas: um experimento de análise filosófica (BAKHTIN, 2016), e o primeiro capítulo da primeira parte de Marxismo e filosofia da linguagem. Problemas fundamentais do método sociológico na ciência da linguagem, intitulado A ciência das ideologias e filosofia da linguagem (BRAIT, 2011, nota 6, p. 186).
\end{abstract}

É a dimensão semiótico-ideológica que possibilita sua natureza reflexivo-refrativa, como explica Medviédev:

\begin{abstract}
Todos os produtos da criação ideológica [...] são objetos materiais e partes da realidade que circundam o homem. É verdade que se trata de objetos do tipo especial, aos quais são inerentes significado, sentido e valor interno. Mas todos esses significados e valores são somente dados em objetos e ações materiais. Eles não podem ser realizados fora de algum material elaborado. [...] Eles tornam-se realidade ideológica somente quando realizados nas palavras, nas ações [...] em uma palavra, em algum material em forma de um signo determinado. Por meio desse material, eles tornam-se parte da realidade que circunda o homem (MEDVIÉDEV, 2012 [1928], p. 48-49, grifos nossos).
\end{abstract}

Retomados esses trabalhos do Círculo, é possível afirmar que a dimensão semiótico-ideológica diz respeito à atualização dos signos em palavras e sua projeção reflexivo-refrativa se realiza em resposta à avaliação ideológica do mundo social, cultural, histórico, impulsionada pelas relações sociais, intersubjetivas, humanas. E se toda palavra pode refletir e refratar diferentes modos de (re)conhecer, compreender e apreender a realidade social, ela se caracteriza, por princípio, pela neutralidade ideológica, ou seja, por sua capacidade de absorver qualquer carga ideológica. Essa questão será abordada a seguir, considerando-se que isso não significa que "a palavra é neutra" quando em uso efetivo. Ao contrário, ela estará sempre carregada de valores dos sujeitos e situações que a colocam em circulação e nela se enunciam. A "mesma" palavra estará permeada de valores diferentes dependendo dos sujeitos que as enunciam em diferentes situações e contextos. Basta pensar, na atualidade brasileira, na carga diferenciada de valores dos signos ideologia e ideológico, quando se tornam palavras enunciadas por diferentes sujeitos, em diferentes situações e esferas de atividade.

\footnotetext{
${ }^{7}$ Conforme Faraco (2009, p. 50-51, grifos do autor), "No processo de referenciação, realizam-se, portanto, duas operações simultâneas nos signos: eles refletem e refratam o mundo. Quer dizer: com os signos podemos apontar para uma realidade que lhes é externa (para a materialidade do mundo), mas o fazemos sempre de modo refratado. E refratar significa, aqui, que com nossos signos nós não somente descrevemos o mundo, mas construímos [...] diversas interpretações (refrações) desse mundo.”
} 


\section{A NEUTRALIDADE IDEOLÓGICO-VALORATIVA DA PALAVRA}

As palavras são tecidas por fios ideológicos diversos e, por vezes, até mesmo contraditórios. Esses fios são tramados no interior das esferas da atividade humana, espaços sociais de gênese, regularização e legitimação das situações de interação, engendrando os variados matizes ideológicos das palavras. Isso significa que toda palavra traz em si marcas sociodiscursivas de esferas, de situações de interação que, em confluência, constituem seus sentidos, seus efeitos de sentido, integrando-a organicamente à situação de interação e à esfera da atividade humana da qual faz parte. De acordo com Volóchinov (2017 [1929/1930], p. 109, destaques do autor), “[...] as formas do signo são condicionadas, antes de tudo, tanto pela organização social desses indivíduos quanto pelas condições mais próximas da sua interação." Nessa perspectiva, é possível compreender a relação entre esferas da atividade humana, ideologias do cotidiano e ideologias sistematizadas:

\footnotetext{
Estabelecemos o acordo de chamar de ideologia do cotidiano a todo conjunto de sensações cotidianas - que refletem e refratam a realidade social objetiva - e as expressões exteriores imediatamente a elas ligadas. A ideologia do cotidiano dá significado a cada ato nosso, a cada ação nossa e a cada um de nossos estados "conscientes". Do oceano instável e mutável da ideologia [do cotidiano], afloram, nascem gradualmente as inumeráveis ilhas e continentes dos sistemas ideológicos: a ciência, a arte, a filosofia, as teorias políticas. Esses sistemas são, no fim das contas, um produto do desenvolvimento econômico, um produto do enriquecimento técnico e econômico da sociedade. Por sua vez, esses sistemas exercem uma influência fortíssima sobre a ideologia cotidiana e na maior parte das vezes lhe dão o tom dominante [...] (VOLOCHÍNOV, 2013a [1930], p. 151-152).
}

A ideologia do cotidiano é compreendida por Volochínov como aquela que penetra integralmente o nosso comportamento, pois “[...] é mais sensível, compreensiva, nervosa, móvel que a ideologia enformada, 'oficial'." (BAKHTIN [VOLOCHÍNOV], 2009 [1927], p. 88, destaques do autor). Entre a ideologia do cotidiano e a ideologia sistematizada há uma relação orgânica:

Os sistemas ideológicos estáveis e enformados das ciências, das artes, do direito etc. cresceram e se cristalizaram a partir do elemento ideológico instável, que através das ondas vastas do discurso interior e exterior banham cada ato nosso e cada recepção nossa. (BAKHTIN [VOLOCHÍNOV], 2009 [1927], p. 88).

É no centro da ideologia do cotidiano que se engendram contradições, que após atingirem certo limite, originam o sistema da ideologia oficial. Esses dois conjuntos ideológicos são antagônicos, pois, ao passo que a ideologia oficial apresenta um conteúdo relativamente estável, a ideologia do cotidiano apresenta conteúdos relativamente instáveis. É uma relação entre instabilidades e estabilidades, própria da tensão viva entre sistemas ideológicos. Distintas e entrelaçadas por contradições, elas formam um complexo contexto semiótico-ideológico. 
A partir daí, podemos compreender que toda esfera da atividade humana gera, regulariza e legitima situações de interação específicas. Essas situações de interação, por sua vez, são organizadas por sujeitos engajados em relações intersubjetivas e que interagem por meio de palavras atravessadas por ideologias do cotidiano e ideologias sistematizadas. Essas palavras são marcadas pelas ressonâncias semântico-ideológicas das esferas e os sentidos das palavras respondem axiologicamente a essas ressonâncias. Segundo Medviédev (2012 [1928], p. 185-187),

\begin{abstract}
A palavra torna-se um material do enunciado apenas como expressão da avaliação social. Por isso, a palavra entra no enunciado não a partir do dicionário, mas a partir da vida, passando de um enunciado a outros. [...] As possibilidades de uma língua tornam-se realidade somente por meio da avaliação.
\end{abstract}

Índices sociais de valor dizem respeito a projeções semântico-valorativas que afetam todo e qualquer signo, isto é, "[...] somente aquilo que adquiriu um valor social poderá entrar no mundo da ideologia, tomar forma e nele consolidar-se (VOLÓCHINOV, 2017 [1929/1930], p. 111, destaques do autor). Toda palavra é apreciativa, especialmente se considerada como um enunciado concreto ou parte de um. Medviédev (2012 [1928], p.185), ao discutir avaliação social, afirma que: "De fato, é impossível compreender [uma palavra] um enunciado concreto sem conhecer sua atmosfera axiológica e sua orientação avaliativa no meio ideológico".

Toda palavra, portanto, traz o potencial da neutralidade ideológico-valorativa. A depender da esfera da atividade humana, das condições da situação de interação, a palavra é atravessada pelas projeções e ressonâncias ideológico-valorativas destas. E são essas projeções e ressonâncias que dão vida à palavra, que dão vida a sua "multiacentuação" (VOLÓCHINOV, 2017 [1929/1930], p. 113). Com isso, toda a palavra é caracterizada pela neutralidade semântico-ideológico-valorativa matizada pela esfera e pelas condições sociais da interação verbal, ou seja, toda palavra é "neutra" em relação à função ideológica, podendo assumir qualquer função ideológica em um dado enunciado (ver as discussões na seção 4 deste artigo). Assim, para cada situação de interação, no interior de uma dada esfera sociodiscursiva, a palavra pode receber diferentes cargas ideológicas, o que caracteriza sua neutralidade.

Embora este artigo tenha escopo bibliográfico, neste ponto, para maior clareza da complexa e pertinente questão da neutralidade ideológico-valorativa da palavra, nos valemos de duas reflexões: a) uma poética, o poema verbo-visual de José Paulo Paes, intitulado sick transit, de onde escolhemos a epígrafe deste artigo, que é também o título do poema, (PAES, 1986); b) outra analítica, a leitura crítica do poema, intitulada PlacaPoema: interdições sinalizadas (BRAIT, 2015, p. 219-224) ${ }^{8}$ textos que mobilizam e

\footnotetext{
${ }^{8}$ Consideramos que é desnecessário transcrever o poema na íntegra, pois ele já está transcrito na leitura feita por BRAIT (2015), aqui mobilizada para exemplificar a neutralidade ideológico-valorativa da palavra liberdade, no poema de José Paulo Paes. O enunciado concreto, do qual a palavra liberdade é o eixo central, apresenta-se por meio de uma composição que indicia um jogo: o título do poema só aparece no sumário (PAES, 1986, p. 9); a epígrafe, assinada Demócrito está isolada no final de uma página (PAES, 1986, p. 62); a foto de uma placa de trânsito destaca-se como atrativo visual (PAES, 1986, p. 63). Essa composição inusitada, articulando partes presentes em diferentes páginas, é que
} 
certificam, em duas esferas de produção, circulação e recepção, a neutralidade ideológico-valorativa da palavra liberdade.

Apenas para resumir drasticamente, a palavra liberdade é surpreendida, pelo olhar do poeta, em uma placa de trânsito, que é por ele fotografada e articulada verbovisualmente para compor, com a epígrafe de Demócrito e o título sick transit, um dos poemas da obra Meias palavras, de 1973, incluída em Poesia reunida, de 1986. Na placa de trânsito, enunciado verbo-visual produzido e regulamentado institucionalmente de forma objetiva para orientar pedestres e motoristas, a palavra liberdade, que compõe a expressão LIBERDADE INTERDITADA, refere-se ao nome de uma avenida paulistana, Avenida da Liberdade, que à época estava interditada em função da reurbanização do bairro da Liberdade. Na placa, portanto, a sequência Liberdade Interditada era compreendida pelos destinatários, sem qualquer problema, como "via pública interditada ao trânsito". Isso graças ao conjunto verbo-visual, ao posicionamento em um ponto específico da cidade e sua função de dispositivo de sinalização.

No momento em que perde sua função de dispositivo de sinalização urbana e, sob a forma de fotografia, cujo autor/enunciador não é mais o Departamento de Trânsito, mas um poeta, ela passa a circular em outra esfera de atividade humana - a esfera artística, literária, poética. E aí, as palavras liberdade e interditada, articuladas entre si e também ao título e à epígrafe, assumem outra carga ideológica, numa espécie de jogo de esconde entre esferas, citação e autoria, apontando para a perversa situação política dos anos 1970 no Brasil. "A composição os redimensiona, harmoniza-os como vozes com nova tonalidade [novo tom avaliativo], escancarando, pelo estilo inusitado e irônico o famigerado e proibido assunto: liberdade interditada" (BRAIT, 2015, p.224).

A partir dessa discussão, podemos pensar no como compreendemos e apreendemos as palavras nas diferentes situações interlocutivas nas quais nos engajamos com outrem. Para Volóchinov (2017 [1929/1930]), essa explicação se assenta na relação entre psiquismo e ideologia, questão discutida a seguir.

\section{A POSSIBILIDADE DE INTERIORIZAÇÃO DA PALAVRA}

Volochínov explica que, em sua época, os trabalhos situavam erroneamente o estudo da ideologia na consciência, quando em verdade:

\footnotetext{
Um signo se opõe a outro signo e que a própria consciência pode se realizar e se tornar um fato efetivo apenas encarnada em um material sígnico. Porque a compreensão de um signo ocorre na relação deste com outros signos já conhecidos; em outras palavras, a compreensão responde ao signo e o faz também com signos. [...] o signo surge apenas no processo de interação entre consciências individuais. E a própria consciência individual está repleta de signos. Uma consciência só passa a existir como tal na medida em que é preenchida pelo conteúdo ideológico, isto é, pelos signos, portanto apenas no processo de interação verbal (VOLÓCHINOV (2017 [1929/1930], p. 95, destaque do autor).
}

permite a concretização da ideia de "neutralidade da palavra", revelando seu potencial significativo, multifacetado. 
Para ele, a consciência individualizada/idealizada nada pode explicar. Mas, ao contrário, quando entendida como fato social e, por consequência, ideológico, resulta em estudo que, de fato, contribui para a compreensão do signo ideológico e, portanto, da palavra:

[...] toda expressão tem uma orientação social. Em consequência, ela é determinada pelos participantes do acontecimento constituído pela enunciação [...]. [...] a expressão de qualquer sensação necessita antes de tudo da linguagem, entendida em seu sentido mais amplo, isto é linguagem exterior e interior. Sem a linguagem, sem a enunciação bem definida, verbal ou gestual, não existe expressão; assim como não existe expressão sem uma real situação social com participantes reais. [...] A linguagem interior é a esfera, o campo em que o organismo passa do ambiente físico ao social. [...] Uma consciência que não se encarna no material ideológico da palavra interior, do gesto, do signo, do símbolo, não existe ou não pode existir. (VOLOCHÍNOV, 2013a [1930], p. 149-151, destaques do autor).

Entendemos, portanto, que a única forma de situar a consciência é na ordem do social-sígnico, ou seja, "A consciência se forma e se realiza no material sígnico criado no processo da comunicação social de uma coletividade organizada” (VOLÓCHINOV, 2017 [1929/1930], p. 97) e somente nesse curso pode ser explicada. A lógica da consciência é a lógica da interação e, como toda consciência é semiotizada, a realidade da consciência segue a realidade do signo ideológico: "A lógica da consciência é a lógica da comunicação ideológica, da interação sígnica de uma coletividade.” (VOLÓCHINOV, 2017 [1929/1930], p. 98).

Desse modo, é possível concluir que a realidade do psiquismo interior é o signo ideológico e que sem material semiótico não há psiquismo. O estudo dialógico da palavra segue esse princípio: o organismo e o mundo exterior se encontram, de forma integrada e confluente, no signo ideológico. Como não há fronteira entre o psiquismo e a ideologia, conforme Volóchinov (2017 [1929/1930]) explica, há de fato uma diferença de grau: “[...] no estágio de desenvolvimento interior, um ideologema vago; só no processo de encarnação ideológica ele é capaz de se tornar claro, se diferenciar e se fixar" (p. 128).

\begin{abstract}
A linguagem interior consiste principalmente de palavras, ou seja, de signos absolutamente materiais, embora elas não sejam pronunciadas em voz alta, mas para si mesmo. Quando nós compreendemos uma palavra ou uma sequência organizada de palavras, em certo sentido traduzimos esta palavra do discurso externo (escutado ou lido) de outro homem para o nosso discurso interno e com isso reproduzimos novamente esta palavra, circundamo-la com outras palavras, encontramos seu lugar particular no fluxo verbal completo de nossa consciência. (VOLOCHÍNOV, 2013c [1930], p. 194, destaques do autor).
\end{abstract}

Volóchinov (2017 [1929/1930]) indaga a respeito de como se realizam as formas sígnicas, entendendo-as como impressões totais dos enunciados (p. 136). A seguir, perseguiremos essa questão. 
Se as formas sígnicas do discurso interior, e podemos acrescentar, do exterior, na materialidade da palavra, se dão sob as impressões da enunciação (VOLOCHÍNOV, 2013b [1930b]), a palavra, enquanto encarnação material do signo ideológico, é concebida como palavra-enunciado.

Fora da enunciação, a palavra só existe no dicionário, mas nesse é uma palavra morta [...] A palavra torna-se palavra somente no intercâmbio comunicativo social vivo, na enunciação real, que pode ser compreendida e avaliada não somente pelo falante mas também pelo seu auditório, seja este potencial ou realmente existente. (VOLOCHÍNOV, 2013 b [1930], p. 195196, destaque do autor).

Isso significa, em termos teórico-metodológicos, que a palavra é entendida como unidade da comunicação discursiva, material das interações verbais, caracterizada por três peculiaridades constitutivo-funcionais: (i) alternância de uso por sujeitos em situação de uso (fala ou escrita); (ii) conclusibilidade e (iii) expressividade semântico-axiológica. Em síntese, a palavra, como forma material do signo ideológico, compartilha das mesmas feições/peculiaridades de qualquer enunciado.

Para Bakhtin (2003a [1951-1953]), a alternância dos falantes é o que delimita o início e o fim da enunciação, ou seja, é o que possibilita os limites entre os já-ditos aos quais o enunciado responde. Bakhtin (2003a [1951-1953]) ainda explica que essa peculiaridade pode se realizar de várias formas, frente aos diversos campos da atividade humana e às distintas formas de interação social das quais participamos. A troca de turnos tem no diálogo real sua forma mais evidente, embora não se restrinja a essa possibilidade.

A segunda peculiaridade do enunciado é a conclusibilidade. Bakhtin (2003a [19511953]) explica que a conclusibilidade é um tipo de aspecto interno da alternância dos sujeitos do discurso, determinando o todo do enunciado, ou seja, aquilo que constitui sua inteireza. Três elementos engendram a conclusibilidade: (i) a exauribilidade semânticoobjetal; (ii) o projeto de discurso ou vontade de discurso e (iii) as formas típicas composicionais e de acabamento.

Sobre o primeiro elemento, o pensador esclarece que o objeto do discurso é, a priori, inexaurível, mas ao se tornar tema do enunciado, ganha uma relativa conclusibilidade nos diferentes campos da vida, bem como em distintas condições de interação. O projeto de discurso, segundo elemento, está diretamente ligado ao primeiro e dá conta da intencionalidade discursiva do falante, delimitando as fronteiras do enunciado. Por fim, as formas típicas composicionais e de acabamento envolvem a escolha de gêneros do discurso, posto que a intencionalidade discursiva, o projeto discursivo, só se realiza a partir da seleção de um determinado gênero, ou seja, a partir de uma forma relativamente estável de construção do todo, que irá mediar a realização desse projeto discursivo.

Como cada gênero traz as ressonâncias ideológico-valorativas da esfera na qual se constitui, circula e é recebido, a palavra (como palavra-enunciado), quando incorporada 
a um gênero, é atravessada por ressonâncias. Os gêneros do discurso não apenas estabilizam relativamente o dizer nas situações particulares e concretas de interação, mas também se orientam duplamente na realidade, como sugere Bakhtin, (2003a [1951-1953]) e também Medviédev:

\begin{abstract}
A totalidade [...] de qualquer gênero orienta-se [...] na realidade de forma dupla, e as particularidades dessa dupla orientação determinam o tipo dessa totalidade, isto é, seu gênero. [...] Cada gênero é capaz de dominar somente determinados aspectos da realidade, ele possui certos princípios de seleção, determinadas formas de visão e de compreensão dessa realidade, certos graus na extensão de sua apreensão e na profundidade de penetração nela. [...] podemos dizer que cada gênero possui seus próprios meios de visão e de compreensão da realidade, que são acessíveis somente a ele. [...] Cada um dos gêneros efetivamente essenciais é um complexo sistema de meios e métodos de domínio consciente e de acabamento da realidade (MEDVIÉDEV, 2012 [1928], p. 193-198).
\end{abstract}

Para Medviédev (2012 [1928]), a dimensão exterior orienta a enunciação de interlocutores específicos e determina as circunstâncias temporais, espaciais e ideológicas do enunciado. A dimensão interior, por sua vez, norteia a interdependência do conteúdo temático, do estilo e da construção composicional do gênero do discurso: "o gênero é a unidade orgânica entre o tema e o que está além dos seus limites" (p. 197). Isso significa que

A realidade do gênero é a realidade social de sua realização no processo da comunicação social. Dessa forma, o gênero é um conjunto de meios de orientação coletiva na realidade, dirigido para seu acabamento. Essa orientação é capaz de compreender novos aspectos da realidade. A compreensão da realidade desenvolve-se e origina-se no processo da comunicação social ideológica. (MEDVIÉDEV, 2012 [1928], p. 200).

Retomando as peculiaridades do enunciado, o terceiro elemento apresentado por Bakhtin consiste na expressividade, que dá conta da "relação emocionalmente valorativa do falante com o conteúdo do objeto e do sentido do seu enunciado." (BAKHTIN, 2003a [1951-1953], p. 289). Ele afirma que não existe enunciado neutro e, portanto, o elemento expressivo sempre irá atravessar a enunciação, e esse atravessamento terá graus e significados vários nos diferentes campos da comunicação discursiva. Além disso, é essa relação emocionalmente valorativa do falante com o objeto do discurso e com o sentido do enunciado que irá determinar o estilo da enunciação, que irá orientar as escolhas léxico-gramaticais e composicionais, assim como a disposição desses elementos na constituição do enunciado. Ele esclarece, ainda, que embora a língua ofereça recursos sintáticos, morfológicos e lexicais para a expressão de uma posição valorativa, as unidades do sistema são neutras em relação a qualquer expressão axiológica. Apesar de, em determinados momentos, sentirmos que dadas palavras (enquanto palavrasenunciados) expressam juízos de valor, isto é, que as palavras carregam posições avaliativas, o aspecto expressivo é possível unicamente no enunciado concreto: "a emoção, o juízo de valor, a expressão, são estranhos à palavra da língua e surgem unicamente no processo do seu emprego vivo em um enunciado concreto." (BAKHTIN, 
2003a [1951-1953], p. 292). O poema de José Paulo Paes, invocado como exemplo, ajuda a concretizar essa reflexão teórica de Bakhtin.

A expressividade da palavra é o elemento que marca seu índice valorativo, que possibilita à palavra receber um determinado valor na situação de interação da qual participa. Como pontua Volóchinov (2017 [1929/1930], p. 111), “[...] somente aquilo que adquiriu um valor social poderá entrar no mundo da ideologia, tomar forma e nele consolidar-se". Toda palavra constitui-se e funciona sob a totalidade da enunciação, engendrando-se à alternância do discurso, à conclusibilidade e admitindo uma coloração axiológica, um valor.

Para o Círculo, a palavra, como palavra-enunciado, é entendida como unidade da comunicação discursiva, necessitando ser estudada em sua concretude em situações de interação específicas (assim como sugerimos anteriormente, com a palavra liberdade). Enquanto realidade concreta, toda palavra-enunciado se constitui em uma situação de interação específica e, acima de tudo, é determinada pelas condições sociais da interação e pelos participantes, que são parte constitutiva dessa dimensão social. Para Volochínov (2013b [1930]), todo pensamento, toda percepção do mundo e, por conseguinte, toda enunciação, tem sempre uma estrutura sociológica e uma orientação social. A vida da palavra-enunciado existe apenas no processo de interação social. Se retirarmos a palavraenunciação dessa realidade que a constitui e a faz funcionar enquanto unidade da comunicação discursiva, restará apenas um material abstrato, pois, de acordo com Volochínov (2013b [1930]) só podemos entender, de fato, o sentido de um enunciado se entendermos sua relação com a vida, sua realidade social, conforme explicações anteriores.

Tudo que foi apresentado nas seções precedentes nos conduz a repensar o estatuto da palavra, não como forma idêntica a si mesma ou como produto do pensamento, mas como construto social, reafirmando a possibilidade de considerar seu estatuto a partir da perspectiva dialógica, ou seja, envolvendo um procedimento teórico e metodológico que exige sua articulação com outros constructos de Bakhtin e do Círculo, caso de signo ideológico, dimensão semiótico-ideológica, interação, esferas de atividade humana, gênero, enunciado, relação entre elementos verbais e não verbais, dentre outros.

\section{POR UM ESTUDO/ESTATUTO DIALÓGICO DA PALAVRA}

É possível, portanto, compreender que o estudo da palavra conduzido pelos escritos de Bakhtin e o Círculo, em especial, mas não exclusivamente, aqueles sobre signo ideológico, nos encaminham para as seguintes considerações teórico-metodológicas:

(i) o signo é o material das formas de (re)conhecer, compreender e apreender a realidade social;

(ii) todo signo é ideológico por natureza;

(iii) a forma de encarnação material dos signos, por excelência, é a palavra;

(iv) toda palavra reflete e refrata realidades;

(v) toda palavra é caracterizada pela neutralidade ideológico-valorativa; 
(vi) a neutralidade ideológico-valorativa diz respeito às múltiplas possibilidades semântico-axiológicas da palavra;

(vii) toda palavra pode ser interiorizada;

(viii) a palavra é entendida como palavra-enunciado.

As considerações teórico-metodológicas acima elencadas não encerram o estatuto dialógico da palavra enquanto signo ideológico, enquanto dimensão semióticoideológica, mas convergem para as discussões postuladas pelos escritos do Círculo, em especial aqueles que trazem, explicitamente, encaminhamentos metodológicos para o trabalho com a língua(gem) sob uma perspectiva dialógico-social. Dentre os vários momentos em que o Círculo se dedica a elencar esses encaminhamentos, podemos evocar Volochínov (2017 [1929/1930]):

\begin{abstract}
A língua vive e se forma historicamente justo aqui, na comunicação discursiva concreta, $e$ não no sistema abstrato das formas da língua nem no psiquismo individual dos falantes. Disso decorre que a ordem metodologicamente fundamentada para o estudo da língua deve ser a seguinte: 1) formas e tipos de interação discursiva em sua relação com as condições concretas; 2) formas dos enunciados ou discursos verbais singulares em relação estreita com a interação da qual são parte, isto é, os gêneros dos discursos verbais determinados pela interação discursiva na vida e na criação ideológica; 3 ) partindo disso, revisão das formas da língua em sua concepção linguística habitual (p. 220, destaques do autor).
\end{abstract}

Dessas etapas depreende-se que o analista inicia o trabalho com o corpus considerando as formas e os tipos de interação para, em seguida, proceder ao exame das formas da língua, aceitando o pressuposto de que a comunicação verbal só pode ser entendida a partir do vínculo com a situação concreta de interação. Em uma perspectiva sociológico-dialógica, portanto, a unidade de análise é o enunciado, unidade discursiva por excelência, envolvendo a situação social ampla (as condições sociais, históricas, culturais, políticas, etc.) e a situação imediata (os interlocutores e seus horizontes ideológico-valorativos) Ao estudar as formas e tipos de interação verbal, o pesquisador procura compreender a dimensão social, histórica e cultural para a qual a palavraenunciado aponta, à qual pertence, refletindo-a e refratando-a.

A segunda etapa refere-se às formas típicas e relativamente estáveis da palavraenunciado, referindo-se ao fato de que a análise da palavra-enunciado se dará a partir de determinado gênero do discurso e as relações entre suas dimensões social, histórica, cultural, levada em conta sua dimensão unicamente verbal e/ou visual, verbo-visual ou mesmo gesto visual, como nas línguas de sinais.

$\mathrm{Na}$ terceira etapa, ao analisar "as formas da língua" conjugando-as às duas etapas anteriores, o pesquisador analisará como, no uso de determinadas palavras-enunciados, os diversos recursos da língua (lexicais, gramaticais, fraseológicos) são agenciados sob a baliza da enunciação. É o momento no qual o pesquisador "embrenha-se" na projeção a partir da qual as palavras-enunciados engendram "potenciais de sentido" e tornam-se temático-valorativas em situações de uso. Novamente, propomos aos leitores deste artigo que retomem a análise da sequência LIBERDADE INTERDITADA, referida no final do item 3.

As explicações de Volochínov (2013b [1930], p.158, destaques do autor) sobre a 
enunciação reiteram, como se verá, sua proposta de 1929/1930. Depois de afirmar que "[...] a essência efetiva da linguagem está representada pelo fato social da interação verbal", que é realizada por uma ou mais enunciações", ele se pergunta: "De que depende e em que ordem ocorre a mudança das formas da linguagem?" e apresenta, como resposta, um esquema, considerando-o como "[...] guia na investigação dessa unidade real da linguagem que chamamos enunciação" ${ }^{\prime 10}$

1. Organização [...] da sociedade.

2. Intercâmbio comunicativo social.

3. Interação verbal.

4. Enunciações.

5. Formas gramaticais da língua.

Somando-se as orientações que se encontram em Marxismo e filosofia da linguagem com as do artigo A construção da enunciação, é perfeitamente possível destacar a preocupação teórico-metodológica do autor, claramente evidenciada como sociológico-dialógica. Nessa perspectiva, o analista parte das questões associadas à organização social, histórica, política, econômica e cultural da sociedade, mas sem encerra-se aí: "Não devemos, obviamente, encerrar-se no exame dos problemas ligados ao estudo das formas e dos tipos de vida econômica da sociedade. Esses problemas são objeto de estudo de outras ciências, as ciências sociais [...]" (p. 158). O movimento teórico-metodológico aponta para os intercâmbios comunicativos, para as esferas da atividade humana, buscando entender suas particularidades axiológicas e a situação de interação que se constitui e funciona no interior desse universo discursivo. A situação "[...] não é senão a efetiva realização na vida real de uma das formas, de uma das variedades, do intercâmbio comunicativo social." (VOLOCHÍNOV, 2013b [1930], p. 159, destaques do autor). Nesse percurso, o olhar recai sobre as enunciações reconhecidas como unidades da comunicação discursiva: “[...] forças vivas organizadoras que, junto com a situação da enunciação, constituem não só a forma estilística, mas também a estrutura puramente gramatical da enunciação" (VOLOCHÍNOV, 2013b [1930], p. 169).

Como em $M F L$, o olhar para as formas gramaticais da língua conclui o percurso analítico: "Uma vez estabelecido que o significado de qualquer enunciação da vida cotidiana depende da situação e da orientação social face ao ouvinte-participante de tal situação, devemos agora examinar a forma da enunciação" (VOLOCHÍNOV, 2013b [1930b], p. 173). Pensamos que essa importantes observações teórico-metodológicas nos ensinam, ainda, que no momento real de análise e diante de enunciados concretos, palavras-enunciado, o corpus certamente determinará as direções e as sequências, aqui exemplificadas didaticamente, mas que não devem ser tomadas como normas rígidas a serem seguidas cegamente. Afinal, os óculos teóricos não podem ser mais importantes que o acontecimento de linguagem escolhido para a análise e interpretação. O pesquisador

\footnotetext{
${ }^{9}$ Nas traduções feitas diretamente do russo, em lugar da expressão interação verbal encontra-se interação discursiva, que aponta para o verbal e o extraverbal.

${ }^{10}$ Os termos enunciação/enunciado (viskázivanie, em russo) são intercambiáveis. A escolha de um ou outro depende do tradutor.
} 
tem o dever da produção de conhecimento diante dos enunciados e não da aplicação mecânica da teoria. Isso vai ficando claro nos escritos de Volochínov e dos demais pensadores do Círculo, o que nos permite, entendendo a palavra como palavraenunciado, seguir os mesmos princípios.

Em consonância com as postulações do Círculo, em especial as de Volochínov, Medviédev e Bakhtin, podemos afirmar que toda palavra é interindividual, posto que nenhum enunciado se constitui fora da alteridade, isto é, da relação necessária com o outro (BAKHTIN, 2003a [1951-1953]). Para esse pensador:

\begin{abstract}
A palavra da língua é uma palavra semi-alheia. Ela só se torna 'própria' quando o falante a povoa com sua intenção, com seu acento, quando a domina através do discurso, torna-a familiar com a sua orientação semântica e expressiva. Até o momento em que foi apropriado, o discurso não se encontra em uma língua neutra e impessoal (pois não é do dicionário que ele é tomado pelo falante!), ele está nos lábios de outrem. (BAKHTIN, 1998 [1975], p. 100, grifo do autor)
\end{abstract}

Ao que se pode acrescentar sua afirmação de que a língua não conserva palavras neutras, de ninguém; ela é totalmente acentuada, ou seja, todas as palavras são povoadas e atravessadas por valores, evocando discursos e contextos outros. É justamente nesse enfrentamento de enunciados e pontos de vista que Bakhtin (2008 [1963]) discute o conceito de relações dialógicas, entendidas como relações semântico-valorativas que somente se concretizam no plano do discurso enquanto língua viva.

\begin{abstract}
A palavra não é um objeto, mas um meio constantemente ativo, constantemente mutável de comunicação dialógica. Ela nunca basta a uma consciência, a uma voz. Sua vida está na passagem de boca a boca, de um contexto para outro, de um grupo social para outro, de uma geração para outra. Nesse processo ela não perde o seu caminho nem pode libertar-se até o fim do poder daqueles contextos concretos que integrou. Um membro de um grupo falante nunca encontra previamente a palavra como uma palavra neutra da língua, isenta das aspirações e avaliações de outros ou despovoada das vozes de outros. Absolutamente. A palavra, ele a recebe da voz de outro e repleta de voz de outros (BAKHTIN, 2008 [1963], p. 232).
\end{abstract}

Ao propor que as relações dialógicas não podem ser estudadas em uma análise estritamente linguística (embora considere essenciais as abordagens linguísticas e as conquistas desse ramo do conhecimento para o conhecimento da língua/linguagem), Bakhtin (2008 [1963]) propõe uma nova abordagem que possibilite a adoção de uma postura dialógica no estudo da língua/ linguagem e, portanto, a compreensão das relações que existem entre os enunciados. Esse novo ramo do conhecimento ele denomina metalinguística (ou translinguística), estudo voltado para a língua viva, língua-discurso. Na verdade, ele está propondo o que hoje denominamos, no Brasil, Análise Dialógica do Discurso (ADD).

Sob a perspectiva da metalinguística, o autor explica que, embora a Linguística proponha caminhos analíticos para a descrição dos elementos sintáticos, morfológicos e lexicais, necessários para que as relações dialógicas se materializem no discurso, essas 
relações (descritivas) pertencem ao campo estritamente linguístico de análise, não abrangendo o contexto social. Assim, Bakhtin discute que, por só existirem no enfrentamento de enunciações concretas (situadas em diferentes interações sociais) e, portanto, só se realizarem no campo do discurso, no campo de estudo da língua viva, as relações dialógicas

[...] são profundamente originais e não podem reduzir-se a relações lógicas, ou linguísticas, ou psicológicas, ou mecânicas, nem a nenhuma outra relação natural. É o novo tipo de relações semânticas, cujos membros só podem ser enunciados integrais (ou vistos como integrais ou potencialmente integrais), atrás dos quais estão [...] sujeitos do discurso reais ou potenciais, autores de tais enunciados. (BAKHTIN, 2003b [1930], p. 330-331, destaque do autor).

Com mais esse conceito, relações dialógicas, aqui trabalhado rapidamente, podemos entender que toda palavra-enunciado é sempre constituída por essas relações, que são relações de sentido e de valor (relações semântico-axiológicas). O estudo das relações dialógicas reitera a característica da palavra como palavra-enunciado, por sua concreta e viva totalidade, em sua autêntica forma de constituição e funcionamento.

\section{CONSIDERAÇÕES FINAIS}

A motivação deste artigo, que poderia parecer uma simples revisão da "literatura", residiu na constatação de que os escritos de Bakhtin e do Círculo, bastante conhecidos e mobilizados em diferentes vertentes do conhecimento e também do ensino-aprendizagem, por vezes requerem um voltar-se a determinados conceitos, noções, categorias oriundas desse pensamento para, na releitura, recuperar elementos fundantes de sua constituição semiótica, sociológica, dialógica. Ao longo deste artigo, procuramos revisitar escritos de Bakhtin e do Círculo com o objetivo de repensar, teórica e metodologicamente, um desses constructos, a palavra, e seu estatuto dialógico, aí implicada, necessariamente, sua dimensão semiótico-ideológica. Para tanto, organizamos nossa discussão a partir do que Bakhtin e o Círculo consideram propriedades caracterizadoras da palavra, a saber, sua natureza semiótico-ideológica; sua neutralidade ideológico-valorativa; sua possibilidade de interiorização; sua essência como ato enunciativo.

Reiteramos que o signo, na perspectiva dialógica, é a forma material da realidade social e que todo signo é ideológico e concretiza diferentes formas/modos de compreender e apreender a realidade social. E que o material da realização concreta do signo é a palavra, sempre atravessada por projeções semântico-axiológicas diversas, que respondem às coerções da situação de interação e do contexto sócio-histórico-cultural em que se insere enquanto produção, circulação e recepção. Assim, toda palavra caracterizase por uma neutralidade ideológica: ela pode assumir qualquer função ideológica em uma dada enunciação. Fomos sensíveis, coerentemente com a perspectiva dialógica, ao fato de que, neste momento que o Brasil atravessa, as palavras ideologia e ideológico, por exemplo, são enunciadas com uma entonação, com uma valoração negativa, que as 
confinam a discursos de um determinado viés. Como se todo discurso, todo signo, todo enunciado não fosse, inescapavelmente, ideológico.

Podemos também afirmar que toda palavra tem a possibilidade de interiorização. Em outras palavras e segundo o Círculo, a linguagem interior consiste de palavras e estas encontram lugar particular nos fluxos verbais da consciência. Há uma síntese dialético/dialógica entre vida interior (psiquismo) e vida exterior (ideologia). A partir dessas considerações, recolhidas nos trabalhos do Círculo, entendemos que a palavra, a palavra-enunciado (a palavra enunciada?!...), caracteriza-se pela alternância interlocutiva, conclusibilidade e expressividade.

Ademais, nossa discussão pretendeu contribuir para as pesquisas no campo da Análise Dialógica do Discurso (ADD), em especial quanto às questões sobre (i) a relação entre signo ideológico e valoração; (ii) a concretude do signo ideológico na palavraenunciado; (iii) as relações entre discurso interior e discurso exterior; além de corroborar (iv) a natureza dialógica da linguagem em sua dimensão semiótico-ideológica. $\mathrm{O}$ artigo, em outras palavras, colabora para as pesquisas contemporâneas em ADD, na medida em que faz uma retomada das considerações em torno da palavra-enunciado, como materialidade do signo ideológico, rediscutindo valoração/axiologia e interiorização/consciência na/da palavra-enunciado.

$\mathrm{O}$ artigo procurou retomar características da palavra-enunciado, discutida por Bakhtin, Volochínov e Medviédev, a fim de compreender como ocorre o diálogo entre os autores e, a partir disso, retomar o caminho epistemológico, teórico e metodológico da abordagem dialógica aí sugerida. Longe de termos aqui uma abordagem, um levantamento exaustivo da questão, esboçamos um contorno possível para, no interior de trabalhos de diferentes épocas, apreender/revisitar esse tema tão caro aos estudos bakhtinianos, à perspectiva dialógica, aos estudos atuais da linguagem - que é o estatuto da palavra, abordado com método e rigor pelos autores dos trabalhos aqui selecionados.

\section{REFERÊNCIAS}

BAKHTIN, M. Questões de literatura e de estética: a teoria do romance. Trad. Aurora Fornoni Bernardini et al. 6. ed. São Paulo: Hucitec Editora, 1998 [1975].

BAKHTIN, M. Os gêneros do discurso. In: BAKHTIN, M. Estética da criação verbal. Trad. Paulo Bezerra. 4. ed. São Paulo: Martins Fontes, 2003a [1951-1953]. p. 261-306.

BAKHTIN, M. Os gêneros do discurso. Organização, tradução, posfácio e notas Paulo Bezerra. São Paulo: Editora 34, 2016.

BAKHTIN, M. O problema do texto na linguística, na filologia e em outras ciências humanas. In: BAKHTIN, M. Estética da criação verbal. Trad. Paulo Bezerra. 4. ed. São Paulo: Martins Fontes, $2003 \mathrm{~b}$. p. 307-335. [1959-1961].

BAKHTIN, M. O texto na linguística, na filologia e em outras ciências humanas: um experimento de análise filosófica. In: BAKHTIN, M. Os gêneros do discurso. Trad. Paulo Bezerra. São Paulo: Editora 34, 2016. p. 71-107.

BAKHTIN, M. Problemas da poética de Dostoiévski. Tradução de Paulo Bezerra. 4. ed. Rio de Janeiro: Forense Universitária, 2008 [1963].

BAKHTIN, M. O freudismo: um esboço crítico. Trad. Paulo Bezerra. São Paulo: Perspectiva, 2009 [1927]. 
BRAIT, B. Placa-Poema: interdições sinalizadas. In: BRAIT, B. Literatura e outras linguagens. São Paulo: Contexto, 2015. p. 219-224.

BRAIT, B.. Polifonia arquitetada pela citação visual e verbo-visual. Bakhtiniana, São Paulo, v. 1, n.5, p. 183-196, $1^{\circ}$ semestre 2011.

FARACO, C. A. Linguagem \& diálogo: as ideias linguísticas do Círculo de Bakhtin. São Paulo: Parábola Editorial, 2009.

GRILLO, S. V. de C. Marxismo, psicanálise e método sociológico: o diálogo de Volóchinov, marxistas soviéticos e europeus com Freud / Marxism, Psychoanalysis and Sociological Methods: Voloshinov's, Soviet and European Marxists' Dialogue with Freud. Bakhtiniana, São Paulo, v. 12, n. 3, p. 54-75, set./dez. 2017.

MEDVIÉDEV, P. N. O método formal nos estudos literários: introdução crítica a uma poética sociológica. Trad. Sheila Camargo Grillo e Ekaterina V. Américo. São Paulo: Contexto, 2012 [1928].

PAES, J. P. sick transit. In: Um por todos. Poesia reunida. São Paulo: Brasiliense, 1986, p. 62-63. [1. ed. Meias palavras, 1973].

VOLÓCHINOV, V. (Círculo de Bakhtin) Marxismo e filosofia da linguagem: Problemas fundamentais do método sociológico na ciência da linguagem. Trad. Sheila Grillo e Ekaterina V. Américo. São Paulo: Editora 34, 2017 [1929-1930].

VOLOCHÍNOV, V. Que é linguagem. In: VOLOCHÍNOV, V. A construção da enunciação e outros ensaios. Tradução de João Wanderley Geraldi. São Carlos: Pedro \& João Editores, 2013a [1930].

VOLOCHÍNOV, V. A construção da enunciação. In: VOLOCHÍNOV, V. A construção da enunciação e outros ensaios. Tradução de João Wanderley Geraldi. São Carlos: Pedro \& João Editores, 2013b [1930].

VOLOCHÍNOV, V. A palavra e suas funções sociais. In: VOLOCHÍNOV, V. A construção da enunciação e outros ensaios. Tradução de João Wanderley Geraldi. São Carlos: Pedro \& João Editores, 2013c [1930].

VOLOCHÍNOV, V. As mais recentes tendências do pensamento linguístico ocidental. In:

VOLOCHÍNOV, V. A construção da enunciação e outros ensaios. Tradução de João Wanderley Geraldi. São Carlos: Pedro \& João Editores, 2013d [1928].

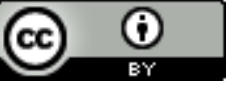

Este texto está licenciado com uma Licença Creative Commons Atribuição 4.0 Internacional. 